as reviewing employment policies and practices to reduce discrimination, establishing support networks for adults to promote positive mental health, and the early detection and treatment of mental illness. The intention is to develop an emotionally resilient and mentally healthy community with access to community-based, comprehensive and costeffective mental health services.

\section{Sources}

Chong, S. A., Mythily, Lum, A., et al (2005) Determinants of duration of untreated psychosis and the pathways to care in Singapore. International Journal of Social Psychiatry, 51, 55-62.
Kua, E. H. (2004) Focus on psychiatry in Singapore. British Journal of Psychiatry, 185, 79-82.

Li, X. (2007) Striking a healthy balance. Straits Times, 7 April, S6.

Lim, C. G., Koh, C. W., Lee, C., et al (2005) Community psychiatry in Singapore: a pilot assertive community treatment (ACT) programme. Annals of the Academy of Medicine, 34, 100-104.

Lim, M. K. (2004) Quest for quality care and patient safety: the case of Singapore. Quality and Safety Health Care, 13, 71-75.

Somjee, G. (1995) Public health policy and personnel in two Asian countries. Journal of Asian and African Studies, 30, 90-105.

World Health Organization (2000) Report 2000 Health Systems: Improving Performance. WHO.

Yeo, C. (2004) Mind Your Mind. Mental health promotion. In Case Studies from Countries (eds S. Saxena \& P. J. Garrison). World Federation for Mental Health \& WHO.

\title{
Mental healthcare in Laos
}

\section{Ken Courtenay ${ }^{1}$ and Chantharavady Choulamany ${ }^{2}$}

${ }^{1}$ Consultant Psychiatrist, Barnet, Enfield and Haringey Mental Health NHS Trust, Unit 5, St George's Estate, London N22 5QL, UK, email Ken.Courtenay@beh-mht.nhs.uk

2Psychiatrist, Mental Health Unit, Mahosot Hospital, Vientiane, Lao PDR, email chantharavady_c@hotmail.com

aos (officially the Lao People's Democratic Republic) is a land-locked country in South East Asia, and one of the three former French colonies of Indochina. Since 1989, when it was opened to foreigners, there has been an influx of non-governmental organisations (NGOs) and tourists. From 1998 tourist numbers have increased every year, and Laos has become the 'must see' destination in a travel industry that craves the exotic. It has an old and rich culture with a diverse population. The climate is tropical, with a cool dry season and a hot wet season, when temperatures reach $38^{\circ} \mathrm{C}$.

Laos is bordered by five countries: China, Thailand, Myanmar, Cambodia and Vietnam. It is equal in area to the UK. The country was subjected to heavy bombing during the Vietnam War, which has left a legacy of unexploded ordnance (UXO) in many rural areas. NGOs undertake the decommissioning of UXO. Some $10 \%$ of the population emigrated during the Vietnam War.

It is the poorest country in the region and $80 \%$ of its population of 5.9 million live in rural areas (World Bank, 2006). Life expectancy is 59 years (UK 78 years) and the child mortality rate is 83 per 1000 (UK 5 per 1000) (World Health Organization, 2006).

Lao people adhere to the principles of Buddhism (60\%) and animism (40\%). Traditionally, people have gained most social support from their families and Buddhist monks. With economic development, these supports are under threat from the many social changes taking place in the country.

\section{Economic and social changes}

Laos is a one-party, communist state established in 1975. It is one of the 50 poorest nations in the world and is described as one of the 'least developed countries' by the United Nations Conference on Trade and Development (2002). Since 1998 economic and social change has been rapid, especially under the influence of neighbouring Thailand. Inevitably, changes are having an impact on the lives of the people. Telecommunications technology has transformed a society that once cultivated isolation from the outside world. Changes on the land have included deforestation and the creation of dams for hydroelectricity. Migration from rural to urban areas, with the displacement of people, especially the minority ethnic groups, has affected social networks, which in turn has had an effect on the mental health of Lao people (Bertrand \& Choulamany, 2002).

\section{Healthcare in Laos}

Health personnel are concentrated in the bigger towns. Access for people in rural areas is difficult because of poor road infrastructure. Consultations with doctors in primary and secondary care are free, as is nursing care. However, patients pay for investigations and medication, as well as the cost of hospital in-patient stays. Medication can be bought without prescription at pharmacies. The government spends $4.6 \%$ of its budget on health (UK 16.1\%) (World Health Organization, 2006).

\section{Mental healthcare}

Two units in Vientiane (the capital city) are the only facilities in Laos that provide in-patient and out-patient mental healthcare. One is dedicated to the military (103 Hospital) while the other, based in Mahosot Hospital, is in the public healthcare system. 
Two senior psychiatrists work at Mahosot Hospital. The professor was educated in Hungary and the second psychiatrist was educated in France. The psychiatric unit opened in 1979 under the guidance of a Soviet psychiatrist. The unit is staffed by these two psychiatrists, a neurologist, ten nurses and four general medical doctors. It has 15 beds. Patients are referred to the unit from the accident and emergency department of Mahosot Hospital and from doctors in other parts of the country; also, families make direct referrals. The duration of stay in the in-patient unit is 21 days, regardless of progress. Patients pay US\$1 per day for their care. Family members provide direct care to their relatives while nurses administer drug therapy. After discharge from the hospital out-patient follow-up is available, but it is often not taken up by those who live far from Vientiane. The out-patient department is open every day to review people living in the community.

The general medical doctors in the service have not received formal training in psychiatry. They work in the in-patient unit, providing day-to-day care and advice on drug therapy. They review those who attend the out-patient department and the accident and emergency department of Mahosot Hospital. There are no psychologists in the service. Psychologists from the university academic department advise on the teaching of psychology to medical students but are not actively involved in the clinical work of the mental health unit. In the main, nursing staff provide direct physical healthcare to in-patients and administer drug therapy. They do not undertake psychotherapeutic programmes. Occupational therapy is not available in the service.

The diagnoses among the in-patients include substance misuse, psychotic disorders, catatonia, delirium, epilepsy and neurotic disorders. The physical conditions on the hospital wards are poor. Air conditioning is not available and so open windows and doors give general ventilation to the wards.

Drug therapy is the mainstay of treatment but the formulary is limited to haloperidol, chlorpromazine, flupentixol, diazepam, carbamazepine and amitriptyline. Private pharmacies sell medication to patients but often families cannot afford to buy it. The adherence to drug regimens is questionable on account of the cost of drugs and erratic out-patient attendance.

\section{Mental health legislation}

Article 18 of the Penal Code relates to the care of people with mental health problems and offending behaviour. There is no legislation on the detention of people who are not suspected of involvement in crime.

\section{Medical education}

Medical undergraduates receive 2 weeks' tuition in psychiatry; however, the course is not popular among students. The academic department is located in Mahosot Hospital but there is a paucity of textbooks, especially ones written in the Thai and Lao languages. The physical conditions of the in-patient unit do not enhance the appeal of working with patients who are mentally ill.

There is no formal postgraduate training for doctors in psychiatry, so doctors must seek it outside Laos. As a result, community doctors, who manage most mental health problems, do not receive training in assessment and treatment. On occasion, they resort to using psychotropic medication.

\section{Problems and solutions}

The economic and social changes of the past decade are affecting the mental health of the people, through the loss of the traditional social systems for supporting and sustaining people with mental illness. The explosion of substance misuse among teenagers and young adults is putting pressure on the psychiatric services and the social cohesion of Lao society. A flexible response to these societal changes is required but is difficult to implement in a country that lacks the infrastructure to support mental health services.

The education of students and postgraduate doctors is poor; further, they have few resources and models of care available to them. The education of staff would help to reduce the stigma attached to mental illness. The four general medical doctors who work in the psychiatric unit in Mahosot Hospital are a resource with great potential because of their interest in working in the service, and yet they have not received training in mental healthcare.

The decrepit state of the in-patient facility reflects the low esteem of mental healthcare in the health service. It contrasts with the state-of-the-art cardiology department in Mahosot Hospital, which has been established by foreign aid. The Ministry of Health needs to invest in mental healthcare to enhance the service that people receive. Improvements in inpatient care are necessary and could happen in conjunction with the development of community care to provide a more robust service for the treatment and after-care of patients. In the absence of established in-patient resources nationwide, there are opportunities to develop local, community-oriented services utilising the health personnel in place to manage mental illness with the support of families and religious leaders. Such innovations would require additional trained personnel at a local level to meet the mental health needs of the people.

Other areas of service need include child mental health, epilepsy, services for people with war-related post-traumatic stress disorder and the development of mental health policy and legislation. The absence of mental health legislation leaves people vulnerable to abuse. The introduction of robust mental health legislation is essential to protect the human rights of patients suffering from mental disorders and prisoners with mental health difficulties.

The problems require investment by the Lao government and foreign aid agencies in health services infrastructure and the education of medical and nursing staff. The current economic and social changes that are taking place in Laos, as it develops economically, provide an opportunity for government to undertake improvements in services that could integrate tradition with modern practice.

\section{References}

Bertrand, D. \& Choulamany, C. (2002) Mental health in the Lao PDR. Juth Pakai, issue 5, 6-10. United Nations Development Programme. 
United Nations Conference on Trade and Development (2002) See http:// www.unctad.org/

World Bank (2005) See http://web.worldbank.org/

World Bank (2006) World Development Indicators Database, April 2006, at http://devdata.worldbank.org/
World Health Organization (2005) Lao People's Democratic Republic. In Mental Health Atlas 2005. See http://globalatlas.who.int/globalatlas/ predefinedReports/MentalHealth/Files/LA_Mental_Health_Profile.pdf

World Health Organization (2006) Lao People's Democratic Republic, at http://www.who.int/countries/lao/

\title{
Psychiatric morbidity among patients on haemodialysis in the Mosul district of Iraq
}

\author{
Hellme Najim MBChB Mosul DPM London MRCPsych ${ }^{1}$, Emad Al-Badrani MBChB Mosul ${ }^{2}$ \\ and Khalid Omar Sultan MBChB Mosul MD ${ }^{3}$
}

${ }^{1}$ Consultant Psychiatrist, Mental Health Unit, Basildon Hospital, Basildon, Essex SS16 5NL, UK, email hellmenajim@yahoo.co.uk ${ }^{2}$ Consultant in Renal Medicine, Department of Medicine, Mosul College of Medicine, Mosul, Iraq ${ }^{3}$ Consultant Physician, Mosul Teaching Hospital, Mosul, Iraq

\begin{abstract}
Datients on chronic haemodialysis experience a wide range of physical and psychological stresses. The specific sources of stress include: loss or threatened loss of possessions; relationship problems (e.g. staff-patient relationships, changed roles within the family); restrictions related to physical health status and the dialysis regimen; loss of body function and impaired body image; increased dependency and aggression; the threat of death; impairment of vocational function and financial security; and decreased participation in leisure, social and community activities (Phipps \& Turkington, 2001). A review of psychological maladjustment in patients on haemodialysis found that about $55 \%$ exhibited significant emotional distress, a prevalence three to five times that found in the general population (Aghanwa \& Morakinyo, 1997). The present study aimed to ascertain the prevalence of psychiatric morbidity among patients attending a renal dialysis unit in Mosul, Iraq.
\end{abstract}

\section{Patients and method}

The renal dialysis unit in Mosul comprises a 12-bed ward with two British graduate consultants and one Arab Board graduate. Haemodialysis and peritonial dialysis are carried out on an in- and out-patient basis. The unit serves the Mosul district, which has an urban population of about 1 million.

A standardised schedule (the Crown-Crisp Experiential Index, CCEI), as translated and validated for use in Iraqi culture by Maghazaji et al (1982), was administered to all patients who attended the unit over a 6 -month period. It is a self-rated, 48-item questionnaire with six scales (anxiety, phobia, obsession, somatic symptoms, depression and hysteria). Patients who were critically ill or who refused to participate were excluded. The questionnaire was also administered over the same period to an age- and gender-matched sample of healthy nursing staff on the unit.

For the statistical analyses, $t$-test, analysis of variance (ANOVA) and regression were used. Because of the small size of the sample, it was decided to set significance at the $10 \%$ level.

\section{Results}

A total of 62 patients attended the unit during the study period; of these, two were too ill to complete the questionnaire, seven refused to participate and two withdrew their consent at a later stage. There were more women than men in the sample (55\%). The majority of participants were under 45 year of age (88\%). Approximately half $(49 \%)$ came from urban areas. Hypertension was the most common cause of renal failure (45\%), followed by renal calculi $(24 \%)$ and glomerulonephritis (20\%); other causes (12\%) were

Table 1 Mean (s.d.) scores on the CCEI scales of patients and controls

\begin{tabular}{|c|c|c|c|c|}
\hline Scale & $\begin{array}{l}\text { Patients } \\
(n=51)\end{array}$ & $\begin{array}{l}\text { Controls } \\
(n=50)\end{array}$ & $t$ & $P$ \\
\hline Anxiety & $7.9(3.1)$ & $5.1(3.1)$ & 8.00 & $>0.1$ \\
\hline Phobia & $4.7(2.7)$ & $2.9(2.2)$ & 5.00 & $>0.01$ \\
\hline Obsession & $8.1(2.9)$ & $5.8(3.1)$ & 4.03 & $>0.01$ \\
\hline Somatic & $7.7(3.0)$ & $3.2(2.4)$ & 8.32 & $>0.1$ \\
\hline Depression & $8.2(3.2)$ & $3.3(2.3)$ & 8.90 & $>0.1$ \\
\hline Hysteria & $5.9(2.7)$ & $7.1(3.1)$ & 2.20 & $>0.05$ \\
\hline
\end{tabular}

Table 2 Mean (s.d.) scores on the CCEI scales of male and female patients

\begin{tabular}{|c|c|c|c|c|}
\hline Scale & $\begin{array}{l}\text { Males } \\
(n=23)\end{array}$ & $\begin{array}{l}\text { Females } \\
(n=28)\end{array}$ & $t^{1}$ & $P$ \\
\hline Anxiety & $6.8(2.8)$ & $9.0(3.3)$ & 2.42 & $<0.05$ \\
\hline Phobia & $4.7(1.8)$ & $4.6(3.5)$ & 2.04 & NS \\
\hline Obsession & $8.7(2.7)$ & $9.4(3.1)$ & 0.80 & NS \\
\hline Somatic & $6.7(3.5)$ & $8.6(2.5)$ & 2.09 & $<0.05$ \\
\hline Depression & $7.5(3.3)$ & $8.8(3.0)$ & 1.56 & NS \\
\hline Hysteria & $5.2(3.0)$ & $6.7(2.4)$ & 1.29 & NS \\
\hline
\end{tabular}

1. $t$-test for unpaired case, degree of freedom $\left(n_{1}+n_{2-2}\right)=43$.

NS, no statistically significant association. 